\title{
Computational simulation of liquid-fuelled HVOF thermal spraying
}

\author{
H. Tabbara, S. Gu* \\ School of Engineering Science, University of Southampton, Highfield, Southampton SO17 1BJ, United Kingdom
}

\section{A R T I C L E I N F O}

\section{Article history:}

Received 11 May 2009

Accepted in revised form 1 September 2009

Available online 9 September 2009

\section{Keywords:}

JP-5000

HVOF

Kerosene

CFD

Gas dynamics

Convergent-divergent nozzle

\begin{abstract}
A B S T R A C T
Liquid-fuelled high-velocity oxygen-fuel (HVOF) thermal spraying systems are gaining more attentions due to their advantage of producing denser coatings in comparison to their gas-fuelled counterparts. The flow through a HVOF gun is characterized by a complex array of thermodynamic phenomena involving combustion, turbulence and compressible flow. Advanced computational models have been developed to gain insight to the thermochemical processes of thermal spraying, however little work has been reported for the liquid-fuelled systems. This investigation employs a commercial finite volume CFD code to simulate the flow field through the most widely used liquid-fuel HVOF gun, JP5000 (Praxair, US). By combining numerical combustion and discrete phase models the turbulent spray flame is captured and the development of supersonic gas flow is revealed. The flow field is thoroughly examined by adjusting the nozzle throat diameter and combustion chamber size. The influence of fuel droplet size on the flame shame shape and combusting gas flow is also examined.
\end{abstract}

(c) 2009 Elsevier B.V. All rights reserved.

\section{Introduction}

High-velocity oxygen-fuel (HVOF) thermal spraying was developed in 1930 and has been commercially available for twenty-five years $[1,2]$. HVOF has several benefits over the more conventional plasma spray technique including a faster deposition rate leading to quicker turnaround, with more durable coatings and higher bond strength, hardness and wear resistance due to a homogeneous distribution of the sprayed particles [3]. HVOF is frequently used in engineering to deposit cermets, metallic alloys, composites and polymers, to enhance product life and performance.

The flow field through a HVOF gun is characterized by a complex combination of combustion and heat transfer, compressible supersonic flow, turbulent mixing and multiphase interactions. A typical HVOF system is initialized at the combustion chamber, where fuel and oxygen are fed in and combusted into a complex gaseous mixture. These gaseous products are then forced through a nozzle which accelerates them to supersonic velocity. The coating in powder form may either be fed by a carrier gas into the combustion chamber or downstream after the convergent-divergent nozzle. The ability of this process to propel the powder particles at high velocity without overheating them is its most salient feature. The powder particles which generally range in size from $5 \mu \mathrm{m}$ to $80 \mu \mathrm{m}$ are softened or melted by the hot gas while being carried to a targeted substrate to build up coatings up to mm thickness.

\footnotetext{
* Corresponding author. Tel.: +44 238059 4760; fax: +44 2380593230. E-mail address: s.gu@soton.ac.uk (S. Gu).
}

HVOF systems are designed to run on either gas or liquid fuels. However, the liquid-fuel HVOF systems (HVOLF) creates a greater momentum output which enables the production of denser coatings with a reduced level of porosity and superior corrosion resistance [4]. The design of HVOLF systems is more complex because the liquid fuel needs to be atomised and efficient combustion is more difficult to achieve due to the variation of kerosene quality. Advanced computational models have been developed to gain an insight to the thermochemical processes of thermal spraying. A thorough review on modelling developments can be found in [5]. Most research has been focused on gas-fuel systems including recent work on HV-2000 [1] (Praxair, US) and Diamond Jet (Sulzer-Metco, Switzerland) [6,7]. The most systematic study for liquid-fuel system is reported for METJET (Metallisation, UK) including the combusting gas flow [8] and the inflight particle dynamics $[9,10]$. However, for the most widely used liquid-fuel gun, JP5000 (Praxair, US), only a single numerical investigation was reported in 1996 [11] without a vigorous discussion on combustion phenomenon or revelation of the complex flow patterns which occur during HVOF thermal spraying.

The properties of thermal spray coatings are dependent on the physical and chemical state of the powder particles on impact, such as the degree of melting, temperature, velocity and oxidant content. The computational study on METJET has shown that the thermodynamic flow field within the HVOF gun is sensitive to several parameters including the nozzle shape, oxygen-fuel ratio, fuel droplet size and combustion chamber pressure. The design of the thermal spray gun is therefore critical in order to achieve consistency and a high performance from the coating. METJET has three injection ports for the fuel/ oxygen mixture while only one inlet is designed for JP5000. This will give rise to substantial differences for the combustion phenomena and 
subsequent flow patterns in the combustion chamber between these two guns. A thorough understanding of the thermochemical processes and the intricate interactions between gas and powder particles will enable more quantitative control of the process parameters to meet stringent requirements.

To fill such knowledge gap, the computational fluid dynamics (CFD) approach successfully tested for the METJET system is applied in this study to model the JP5000 gun. Investigation is performed to examine the effects of gun geometry on the combusting gas flow. The results focus on kerosene combustion, the formation of supersonic flow and its expansion within the standoff distance. Further study will follow for the particle dynamics, which will be reported later for the JP5000 gun.

\section{Model description}

\subsection{Model overview}

A schematic diagram of the working JP5000 is illustrated in Fig. 1 highlighting the fuel-oxygen inlet, the combustion chamber, the convergent-divergent (CD) nozzle and barrel. The position of the powder feeders are shown, but are not included in the simulation. A mixture of fuel and oxygen is injected into the combustion chamber through the central inlet. Unlike the gas-fuel system where powder is injected into the centre of the combustion chamber, the powder particles are introduced downstream of the $C D$ nozzle using a carrier gas. The axisymmetric gun design can be well represented by a 2D simulation domain which is adopted in this study, as depicted in Fig. 2. The mesh within the combustion chamber consists of 90 axial nodes and 50 radial nodes, and 120 and 115 axial nodes are present for the $\mathrm{CD}$ nozzle and barrel respectively. The external region covers a practical stand of distance of $300 \mathrm{~mm}$. The grid around the nozzle and the free jet region has been successively refined in a grid sensitivity study in order to accurately capture steep variations in flow properties due to the effects of compressibility. Further refinement is applied to the oxygen-fuel inlet along the axis to improve the flame contours. Finally, a total of 26,000 cells proved suitable. The numerical modelling techniques have been described mathematically in [8] and are omitted here for brevity. The geometric parameters and the working conditions for the simulation are summarized in Table 1.

\subsection{Mathematical models}

The same formulas for gas flow, turbulence and combustion in [8] are adopted in this simulation. More detailed investigation on the droplet evaporation is carried out and the fuel droplet model is described as follows.

The fuel droplets mixed with oxygen are injected into the combustion chamber at the inlet boundary. The acceleration of each droplet particle is calculated using Newton's second law, equating the inertia of each droplet with the forces applied by the continuum,

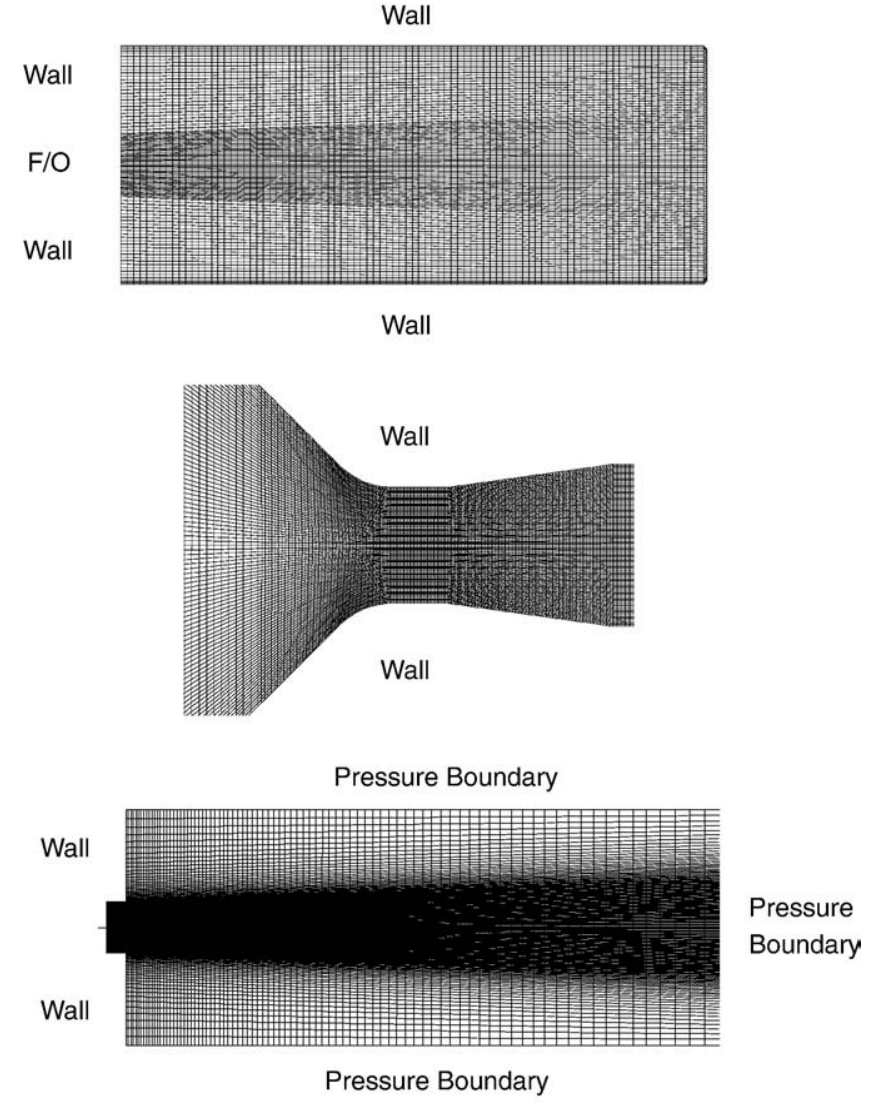

Fig. 2. Grid refinements for the combustion chamber (top), CD nozzle (middle) and standoff region (bottom).

described by Eq. (1). Subsequently, the trajectory of each droplet is tracked by computing its displacement through time.

$\frac{d u_{\mathrm{p}}}{d t}=F_{\mathrm{D}}\left(u-u_{\mathrm{p}}\right)+F_{\mathrm{x}}$

where the drag force per unit particle mass, $F_{\mathrm{D}}\left(u-u_{\mathrm{p}}\right)$, is computed from Eq. (2).

$F_{\mathrm{D}}=\frac{18 \mu}{\rho_{\mathrm{p}} d_{\mathrm{p}}^{2}} \frac{C_{\mathrm{D}} \operatorname{Re}}{24}$

The drag coefficient $C_{\mathrm{D}}$ [12] is given by Eq. (3).

$C_{\mathrm{D}}=a_{1}+\frac{a_{2}}{\operatorname{Re}}+\frac{a_{3}}{\operatorname{Re}^{2}}$

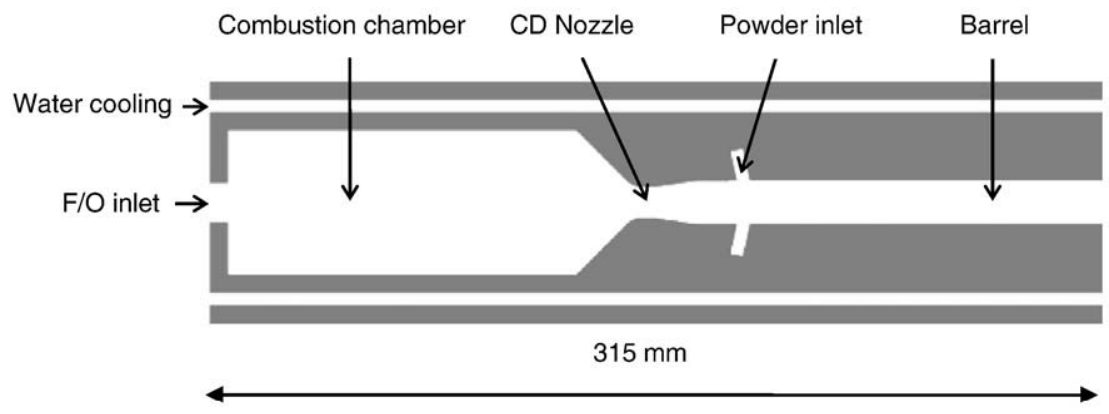

Fig. 1. Schematic diagram of JP5000. 
Table 1

Summary of geometric parameters and working conditions.

$\begin{array}{ll}\text { Geometric parameter } & 111.1 \mathrm{~mm} \\ \text { Barrel length } & 11.0 \mathrm{~mm} \\ \text { Barrel entrance diameter } & 11.1 \mathrm{~mm} \\ \text { Barrel exit diameter } & 92.5 \mathrm{~mm} \\ \text { Combustion chamber length } & 37.8 \mathrm{~mm} \\ \text { Combustion chamber diameter } & 7.9 \mathrm{~mm} \\ \text { Nozzle throat diameter } & \\ \text { Working conditions } & \text { Flow rate: } 0.007 \mathrm{~kg} / \mathrm{s} \text {, temperature: } 300 \mathrm{~K} \\ \text { Fuel } & \text { Flow rate: } 0.022 \mathrm{~kg} / \mathrm{s} \text {, temperature: } 300 \mathrm{~K} \\ \text { Oxygen } & \text { Pressure: } 101325 \mathrm{~Pa} \text {, temperature: } 300 \mathrm{~K} \\ \text { Atmosphere } & \text { Temperature: } 350 \mathrm{~K} \text {, non-slip } \\ \text { Internal wall boundary } & \end{array}$

The relative Reynolds number is defined by Eq. (4).

$\operatorname{Re}=\frac{\rho d_{\mathrm{p}}\left|u_{\mathrm{p}}-u\right|}{\mu}$

As the droplets are dispersed through the continuous flow field, they exchange mass, momentum and energy. While the trajectory of each droplet is calculated using the mean velocity of the continuous phase, the dispersion of these droplets is deduced by the turbulent velocity component. The number of particles in this model represents the number of tries used by the probability based solver to compute the random effects of turbulence on the discrete droplets. The velocity fluctuations are a function of time and remain constant over a period defined by the characteristic lifetime of an eddy within the continuous phase. The time spent in turbulent motion along the particle path is approximated by the $k-\varepsilon$ model using Eq. (5).

$T_{\mathrm{L}}=0.15 \frac{k}{\varepsilon}$

When the temperature of a single droplet within the fuel spray is lower than its vaporization temperature the droplet temperature is controlled by convective heat transfer between itself and the gaseous phase in which it is submersed. The Ranz and Marshall correlation $[13,14]$ given in Eq. (6) is used to calculate the convective heat transfer coefficient between the droplet and the gaseous continuum.

$N u=\frac{h d_{\mathrm{p}}}{k_{\infty}}=2.0+0.6 \operatorname{Re}_{d}^{\frac{1}{2}} \operatorname{Pr}^{\frac{1}{3}}$

When the droplet temperature surpasses the vaporization temperature the vaporization law is initialized and the reduction of the droplet's mass begins to reduce in accordance to Eq. (7).

$m_{\mathrm{p}}(t+\Delta t)=m_{\mathrm{p}}(t)-N_{i} A_{\mathrm{p}} M_{\omega, i} \Delta t$

where,

$N_{i}=K_{\mathrm{c}}\left(C_{i, s}-C_{i, \infty}\right)$

$C_{i, s}=\frac{p_{\text {sat }}\left(T_{\mathrm{p}}\right)}{R T_{\mathrm{p}}}$

$C_{i, \infty}=X_{i} \frac{p_{\mathrm{op}}}{R T_{\infty}}$

The mass transfer coefficient is evaluated through the Sherwood number correlation $[13,14]$, given by Eq. (8).

$k_{\mathrm{c}}=\frac{D_{i, \mathrm{~m}}}{d_{\mathrm{p}}}\left(2.0+0.6 \operatorname{Re}_{d}^{\frac{1}{2}} S c^{\frac{1}{3}}\right)$
The following assumptions have been applied to the modelling of the fluid droplets:

- The volume fraction occupied by the liquid-fuel droplets is sufficiently small i.e. less than $10 \%$. Therefore the number of collisions between liquid droplets is presumed negligible. Their volumes in space are simply modelled as overlapping without physical interaction, and therefore the droplets do not collide or coalesce.

- The droplets do not break up into smaller elements, even during evaporation. The droplets do not react while in their liquid phase before evaporating.

- The density of the droplets is much higher than the gaseous phase. Hence the effects of the pressure gradient force and the virtual mass force are neglected.

- The impact of gravity is neglected due to high horizontal velocities and high-velocity gradients within a relatively small domain.

- Liquid sprays reportedly radiate negligibly [15] and therefore a radiation model is omitted.

- The fuel droplets remain spherical.

- All droplets are identical at the inlet, with the same diameter, temperature etc.

- The liquid droplets are assumed to have no internal thermal resistance and therefore have a uniform temperature throughout.

- The partial pressure of fuel vapour at the surface of each droplet is equal to the saturated vapour pressure at the temperature of the liquid droplet.

\section{Results and discussion}

A validation was carried out first to compare the model prediction with temperature measurement at the exit of a JP5000 thermal spray gun [2]. Fig. 3 shows a high level agreement between the computational and experimental results.

\subsection{Gas flow characteristics}

The premixed, steady-state flame is shown in Fig. 4. The flame itself is detached from the inlet port with an expected conical heating zone. The combustion reaction relies on the evaporation of the fuel droplets, and this evaporation process occurs most rapidly at the outside edge of the inlet jet stream, owing to the higher temperature of the gaseous mixture. In premixed liquid-spray combustion the development of a flame can be summarized by a primary preheating zone (warming of liquid droplets), secondary heating zone (warming of liquid droplets and vaporization) and a reaction zone. The chemical reaction is initiated when the gaseous fuel and oxygen reach their activation energy, and may occur simultaneously with the second preheat zone in the case of larger, less volatile droplets. However, the employed eddy-dissipation turbulent-chemistry model [16] initiates a

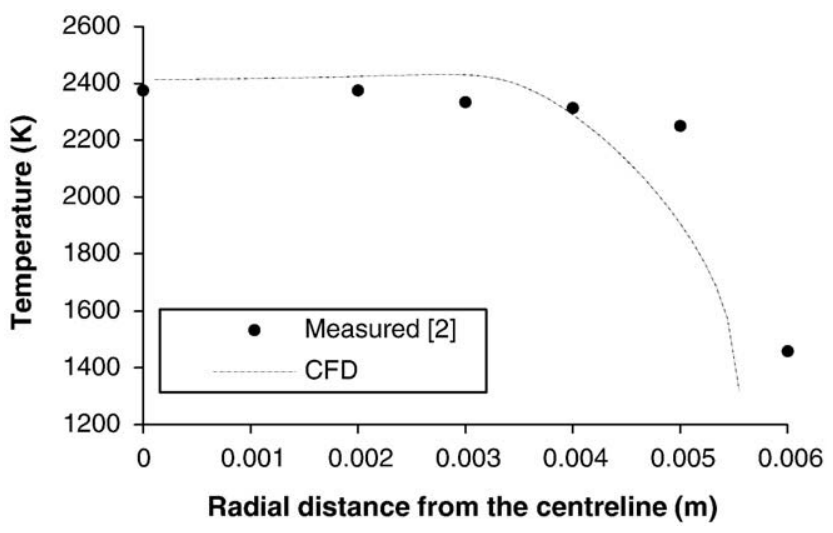

Fig. 3. Comparison of measured and CFD modelled temperatures at the exit of JP5000. 


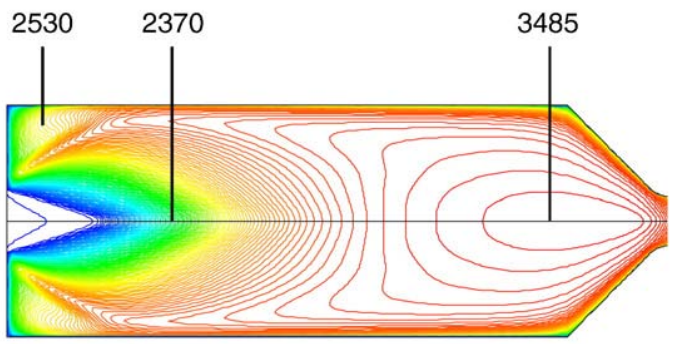

Fig. 4. Combustion chamber temperature $(\mathrm{K})$ contours illustrating the flame shape.

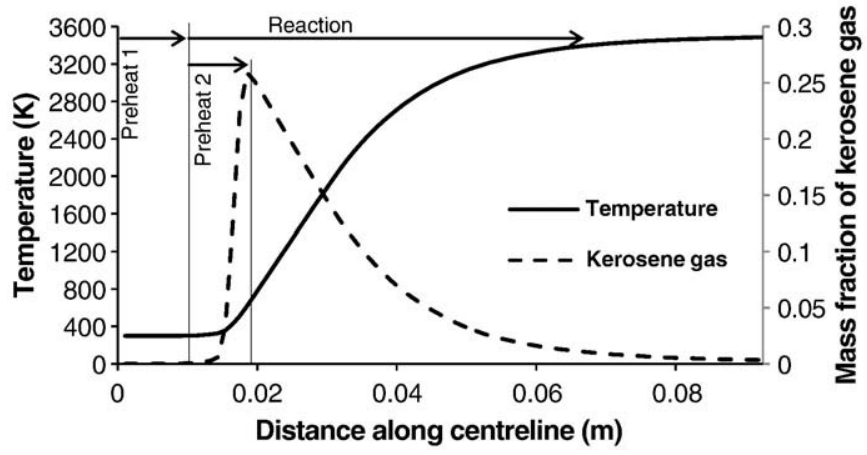

Fig. 5. Graphical representation of the flame development.

reaction as soon as evaporation occurs and therefore completely overlaps the second preheat zone, as illustrated in Fig. 5.

The compressed gases under high pressure are forced through the $\mathrm{CD}$ nozzle and a rapid rise in velocity occurs. At the throat the flow is chocked at mach one. Two small shocks follow as the gas expands and accelerates through the divergent section, marked by slight increases in temperature along the centreline (Fig. 6). Several shocks occur at the exit of the $\mathrm{CD}$ nozzle due to the expansion of the supersonic gas and strong reflections at the solid internal surface of the barrel, which are characterized by fluctuations in temperature along the centreline (Fig. 6). An under-expanded flow regime at the exit of the barrel is present, enforced by a slightly subcritical atmospheric back pressure. The fluctuations in velocity and pressure at the exit of the barrel are created by the flow periodically over expanding and then reconverging above and below atmospheric pressure (Fig. 7). These adjustments continually overshoot due to the boundary communicating with the jet by sound waves, which naturally travel slower than the bulk supersonic flow. Criss-cross shock waves form shock diamonds created by converging sound waves. Rarefaction fans spray around the corners of the barrel exit and the oscillating jet boundary (Fig. 7). As the gas jet passes through the region of rarefaction fans it is expanded and cooled, and through the shock diamonds, the gas is compressed and heated. The convergence points of the incident shocks at the centreline are marked by peaks on the centreline velocity profiles (Fig. 8)

\subsection{Fuel droplet size}

The gas flow characteristics are evaluated by varying the fuel spray droplet diameter between 0.1 and $10 \mu \mathrm{m}$. The results show that for fuel droplets less than $5 \mu \mathrm{m}$ the fuel completely reacts within the combustion chamber. However, above this size, a small amount of gaseous fuel at the centre of the flame enters the $C D$ nozzle and continues to react (Fig. 9). For this reason there is a noticeable difference in the gas temperature profile through the combustion chamber, $\mathrm{CD}$ nozzle and through the first half of the barrel for droplets of $5 \mu \mathrm{m}$ diameter and above (Fig. 6). Half way along the barrel the fuel has completely reacted and the flow regimes for each case converge to similar values. The velocity regimes through the system are less sensitive to the unburnt gaseous fuel and for cases where the fuel droplet diameter is $7.5 \mu \mathrm{m}$ or less the velocity profile is negligibly affected. For the $10 \mu \mathrm{m}$ case the largest amount of fuel exited the combustion chamber causing a reduction of roughly $100 \mathrm{~ms}^{-1}$ throughout (Fig. 8).

The radial temperature profiles through the combustion chamber at quarterly intervals along the centreline (Fig. 10) summarize the variations in flame shape for varying droplet size, and show that for droplets below $1 \mu \mathrm{m}$ there is negligible difference in flame shape. On the other hand, for droplets greater than $1 \mu \mathrm{m}$ the preheating process is prolonged because larger droplets take longer to reach their critical vaporization temperature and the total evaporation rate is reduced due to a smaller total surface area. As a result the flame is stretched along the centre of the combustion chamber.

At the first quarter the $10 \mu \mathrm{m}, 7.5 \mu \mathrm{m}$ and $5.0 \mu \mathrm{m}$ droplet scenarios are in their preheating stage along the centreline and hence the continuum is yet to experience an increase in temperature. However, the preheating zones for the $2.5 \mu \mathrm{m}, 1.0 \mu \mathrm{m}$ and $0.1 \mu \mathrm{m}$ droplets are surpassed by this stage and the temperature of the gaseous continuum has risen due to chemical reaction. The temperature profiles for the different droplet scenarios converge roughly half way along the radial distance from the centreline and this pattern is repeated along the length of the combustion chamber, suggesting that varying the droplet size would make a negligible impact on the amount of energy dissipated through the combustion chamber surface.

Fig. 11 illustrates the recirculation zones at the inlet end of the combustion chamber, and show that for larger droplets the size of the recirculatory region is increased. However, due to lower rates of

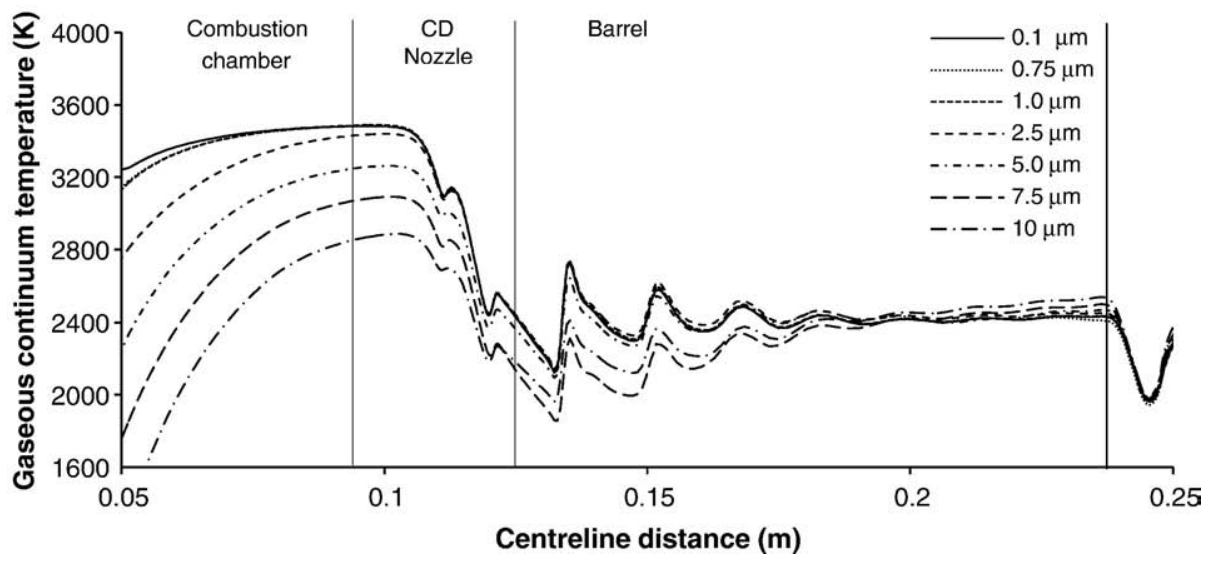

Fig. 6. Centreline temperature profile for different fuel droplet sizes. 

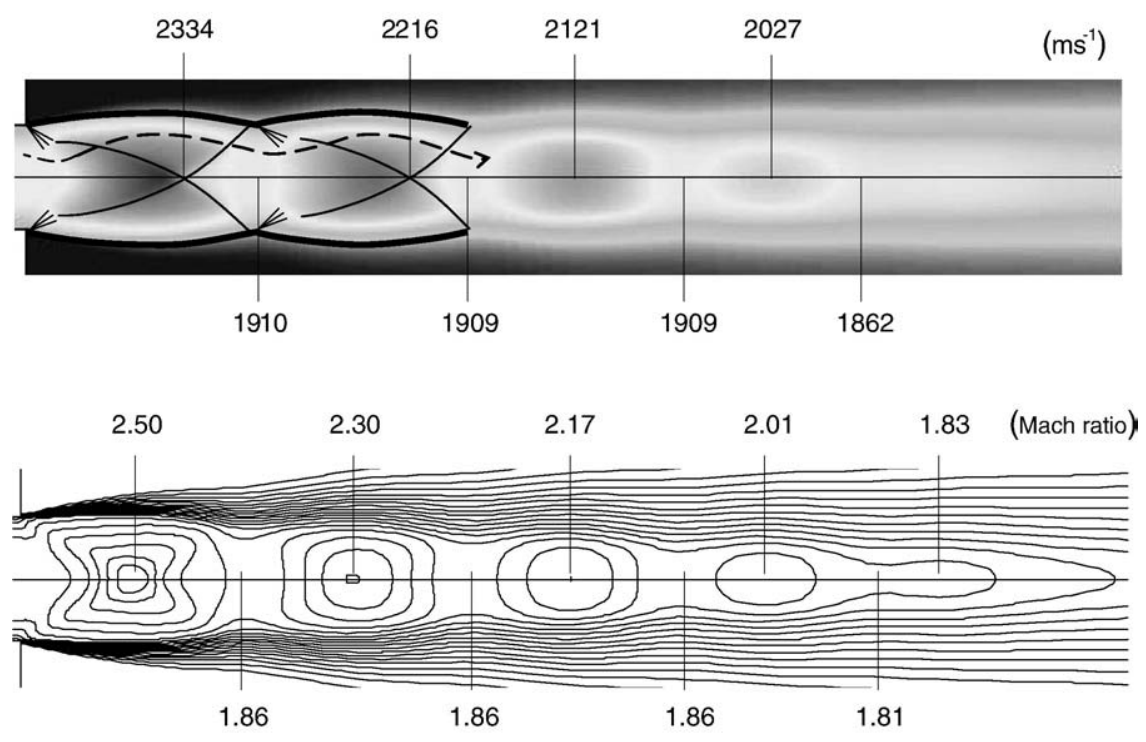

Fig. 7. Variations in velocity (top) and Mach number (bottom) through the exterior under-expanded jet.

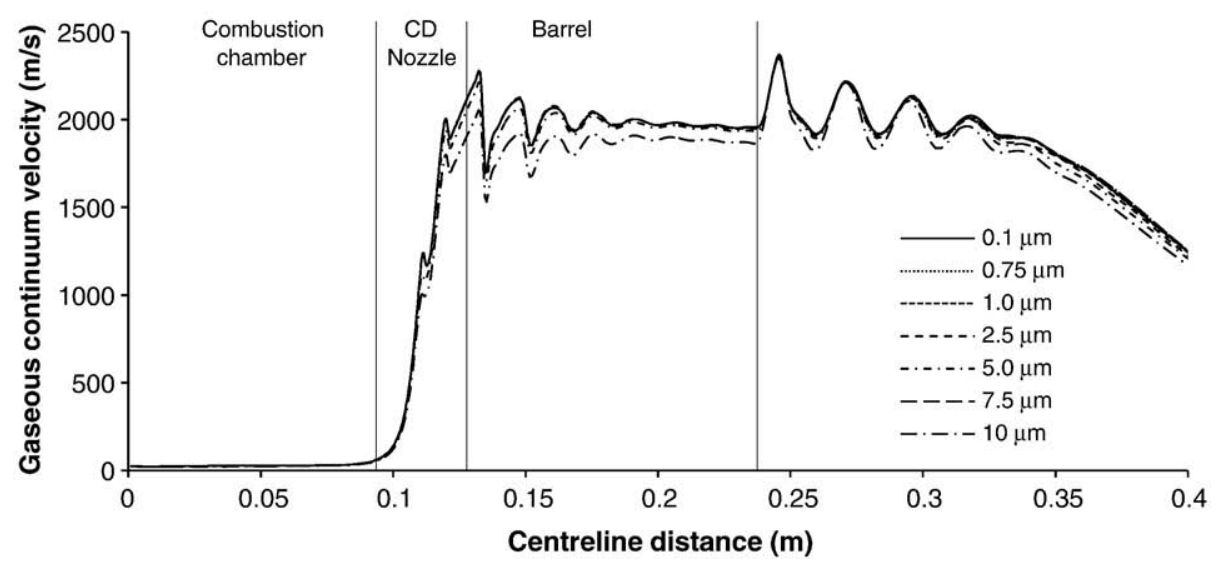

Fig. 8. Variation in gaseous continuum velocity along the centreline for different fuel droplet diameters.

evaporation and a lower rate of production of gaseous products the intensity is reduced. In this zone the velocities are relatively low and at the corner of the combustion chamber soot accumulation is likely to occur. The sharpe corner also creates an area of high stress concentration. In some HVOF designs it may be chamafered, which helps to alleviate these problems. However, the flame within the combustion chamber may tend to be drawn to the wall if the chamfer resides to close, leading to inefficient combustion.

\subsection{Throat diameter}

The diameter at the throat of the $\mathrm{CD}$ nozzle is increased and decreased by $20 \%$ in order to investigate the impact on the flow regime. Figs. 12 and 13 show that such changes make a negligibly impact on the upstream flow profiles within the combustion chamber, however the gas flow characteristics are largely altered through the $\mathrm{CD}$ nozzle, within the barrel and at the barrel exit. At the exit the difference in pressure and back pressure determines the type and intensity of the flow regime. Greater velocity oscillations at the exit of the barrel imply a greater degree of mixing and axial momentum reduction for the gaseous flow. By increasing the flow velocity the pressure of the flow at the exit of the barrel can be reduced towards atmospheric pressure and as a result the magnitude of the fluctua- tions in velocity and temperature which are brought about by the under-expanded flow regime can be lowered.

By increasing or decreasing the throat diameter the gaseous products in the combustion chamber are compressed to a lesser or greater degree respectively. For an increase in compression higher velocities can be attained through the system. An increase in kinetic energy incurs a decrease in thermal energy and hence a lower temperature profile for a faster travelling gas flow is produced. Fig. 12

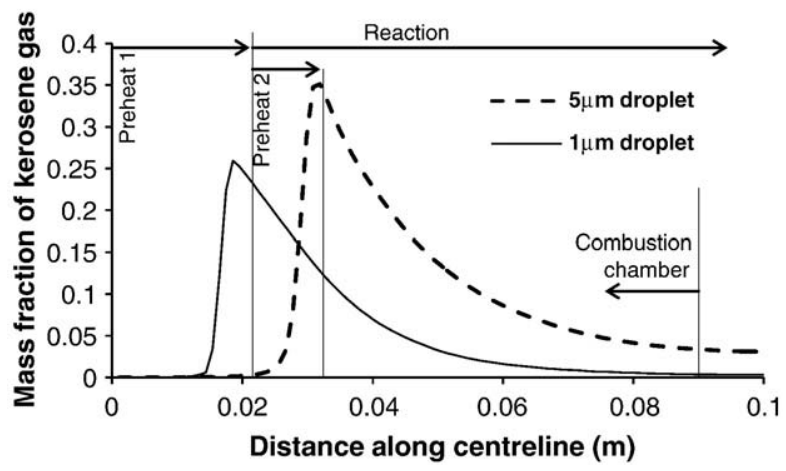

Fig. 9. Flame development for $5 \mu \mathrm{m}$ droplet scenario with $1 \mu \mathrm{m}$ comparison. 


\section{a) $x / X=0.25$}

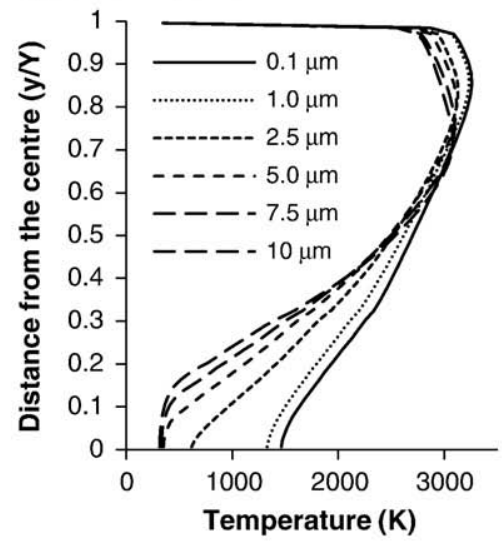

c) $x / X=0.75$

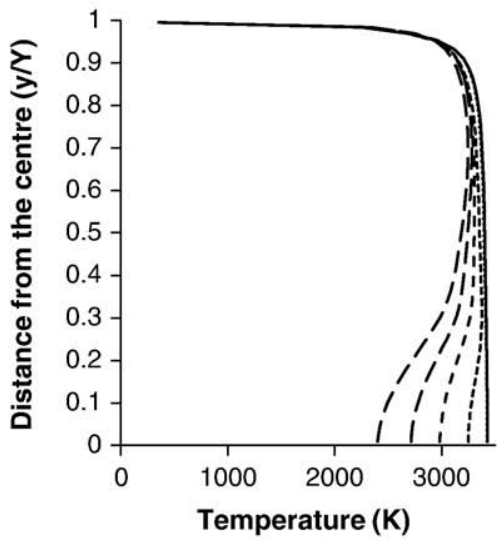

b) $x / X=0.5$

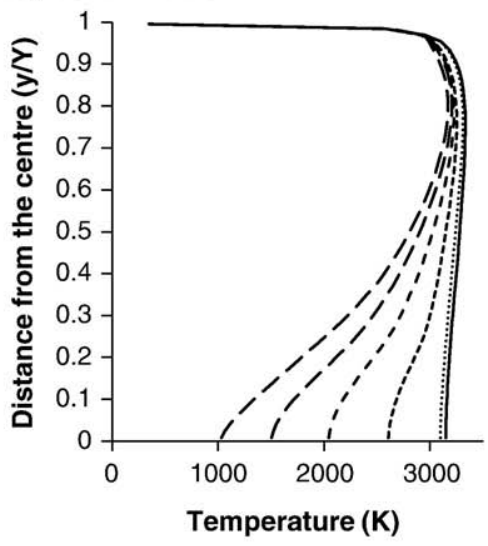

d) $x / X=1.0$

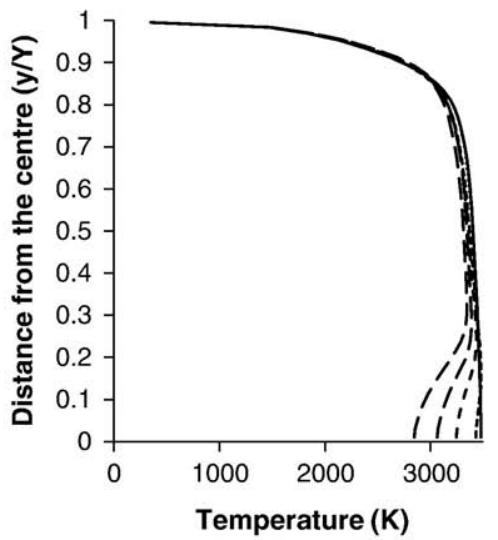

Fig. 10. Radial temperature profiles at quarterly intervals through the combustion chamber for variations in fuel droplet sizes.

highlights the importance of the exterior jet design as this region contributes significantly to the powder particle heating. The 20\% decrease in throat diameter creates a flow of almost perfect design condition which is only slightly under-expanded. As a result the temperature and velocity oscillations diminish due to less intense rarefaction waves. This design alteration maximizes the gas velocity in the free jet region and at the same time prevents overheating of the powder particles. However, the reduction in throat diameter not only enforces an increase in velocity downstream but also causes a compression of upstream gas, which effectively heightens the combustion chamber pressure. Results indicate that a $20 \%$ reduction in throat diameter will induce roughly a $60 \%$ increase in pressure inside the combustion chamber. By altering the $\mathrm{CD}$ nozzle throat diameter the combustion chamber pressure is significantly altered and therefore requires careful consideration.

\subsection{Combustion chamber size}

The combustion chamber length is gradually reduced in $20 \%$ increments and the effects on the gas flow are investigated.

By reducing the combustion chamber length by $40 \%$ the velocity and temperature profiles through the system are unaltered. However, for a reduction of $60 \%$ a large percentage of fuel enters the $C D$ nozzle as quantified by Fig. 14. The gaseous fuel which escapes the combustion chamber continues to react through the nozzle and barrel. Comparing the reaction rate with the corresponding velocity profile
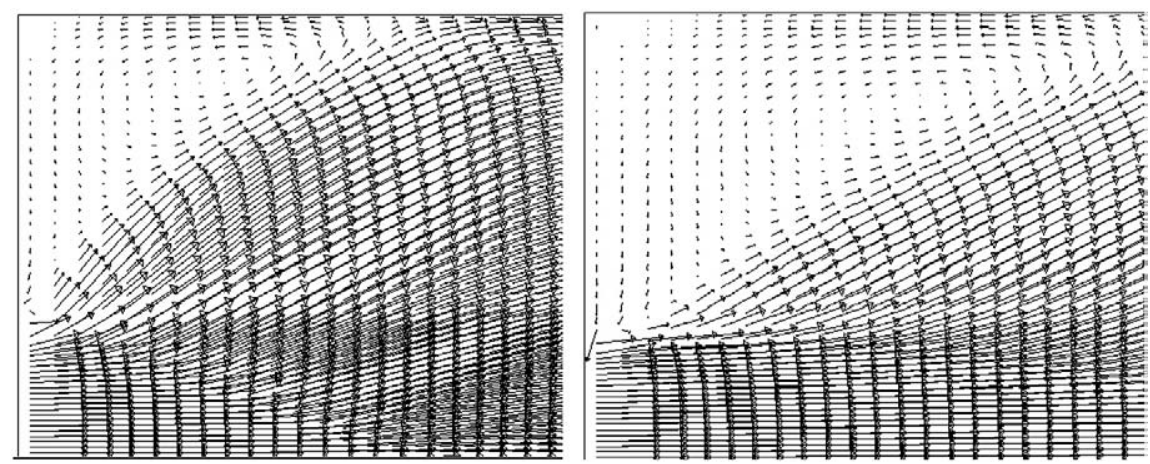

Fig. 11. Recirculation in the combustion chamber. Droplet diameter $=0.1 \mu \mathrm{m}$ (left). Droplet diameter $=10 \mu \mathrm{m}$ (right). 


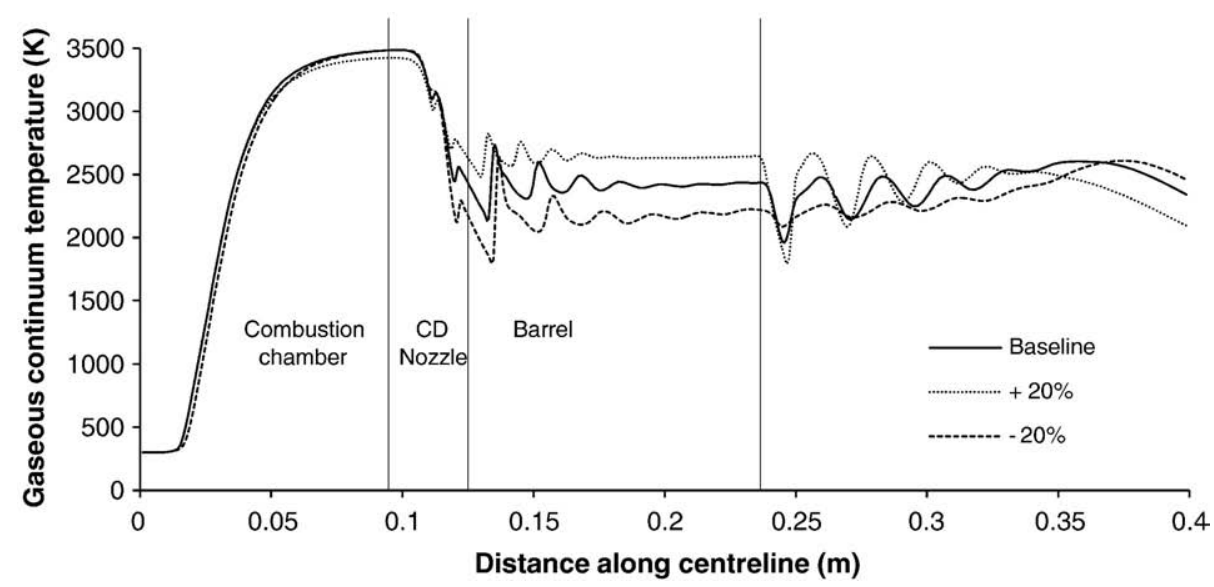

Fig. 12. Variation in gaseous continuum temperature along the centreline for different nozzle configurations.

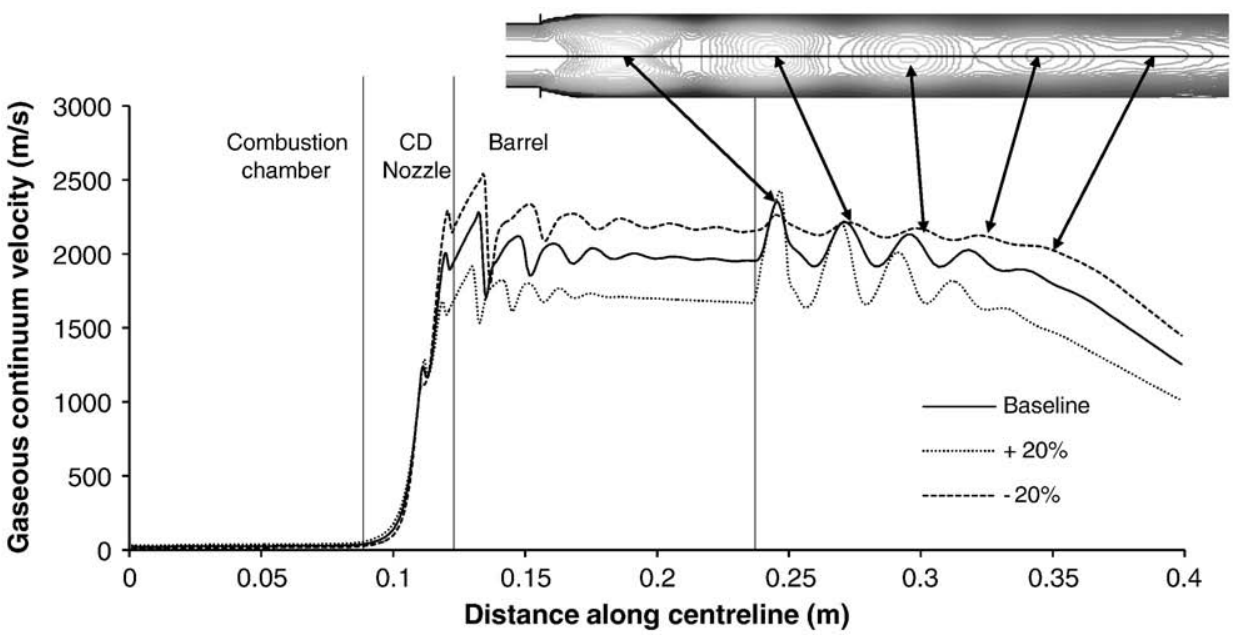

Fig. 13. Variation in gaseous continuum velocity along the centreline for different nozzle configurations.

for the $60 \%$ reduction shows the reaction rate peaking when the flow experiences a shock (Fig. 15). This phenomenon is created by heightened levels of turbulence in areas of steep velocity gradients.

Radial temperature profiles at quarterly intervals through the combustion chamber for the four different combustion chamber lengths (Fig. 16) show little variation when the combustion chamber is reduced by $20 \%$. With a $40 \%$ reduction only a small amount of fuel exits the combustion chamber and leads to a slightly lower than expected temperature at the exit of the combustion chamber along the centreline (Fig. 16c).

The stumped temperature profiles in $16 \mathrm{c}$ and $16 \mathrm{~d}$ at the first quarter highlight the presence of recirculation zones. These regions reduce the temperature near the wall and therefore help to reduce the amount of energy dissipated through the internal surface. The size

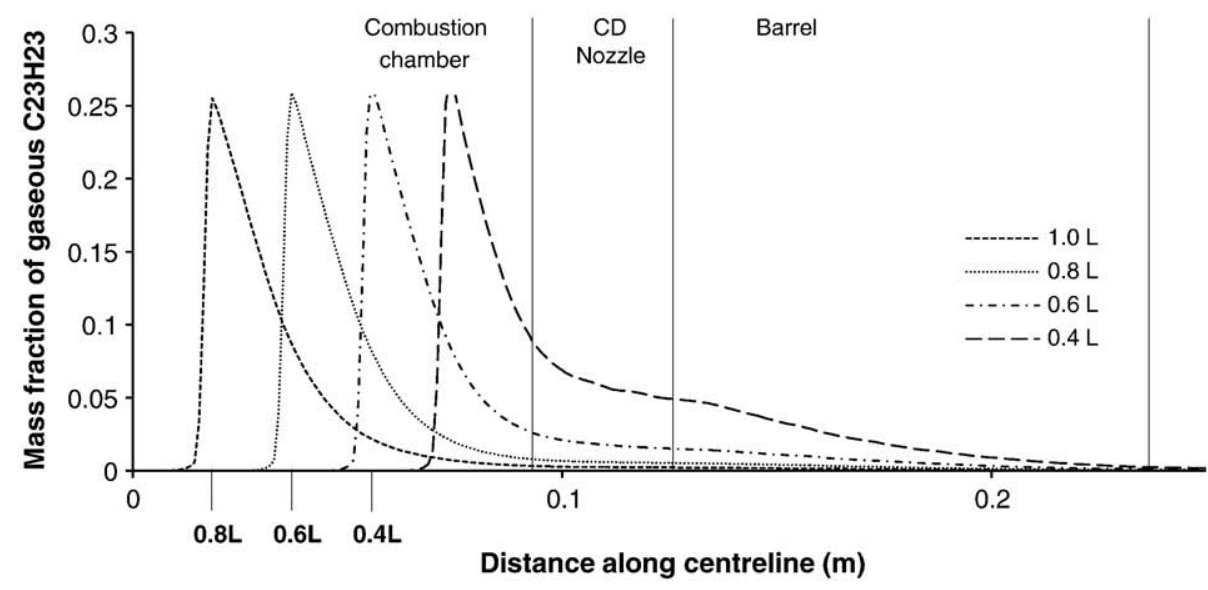

Fig. 14. Mass fraction of gaseous fuel along the centreline for each combustion chamber length reduction. 


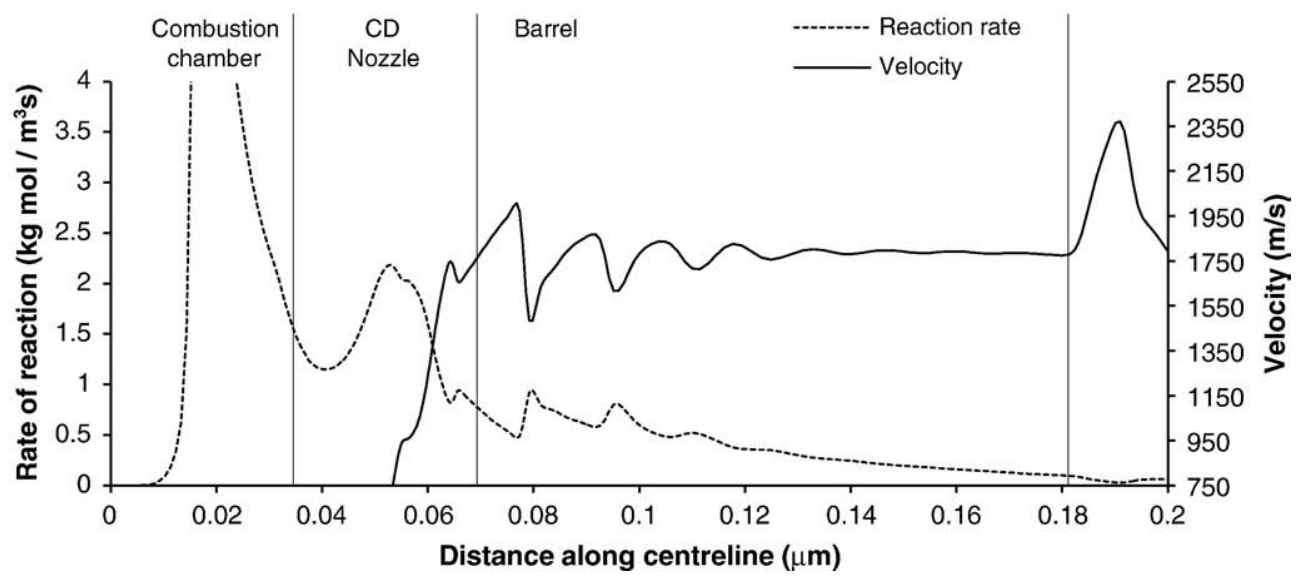

Fig. 15. Comparison of reaction rate and velocity fluctuations along the centreline for $L=40 \%$.

and intensity of the recirculation region remain unaffected by the changes in combustion chamber length and therefore gradually covers a larger proportion of the internal surface as the length of the combustion chamber is reduced.

Results from this investigation indicate that a reduction in the combustion chamber length by $20 \%$ for the baseline model is possible without risking an excessive amount of fuel exiting the combustion chamber, and this reduction can be expected to make a negligible difference to the temperature and velocity profiles through the system. The heat transferred through the internal surface of the combustion chamber can be expected to be reduced by at least the same factor due to the surface area reduction as well as the larger proportion of recirculation at the surface.

\section{Conclusion}

A premixed steady-state flame and compressible combustion flow has been simulated within a kerosene-fuelled HVOF thermal spray

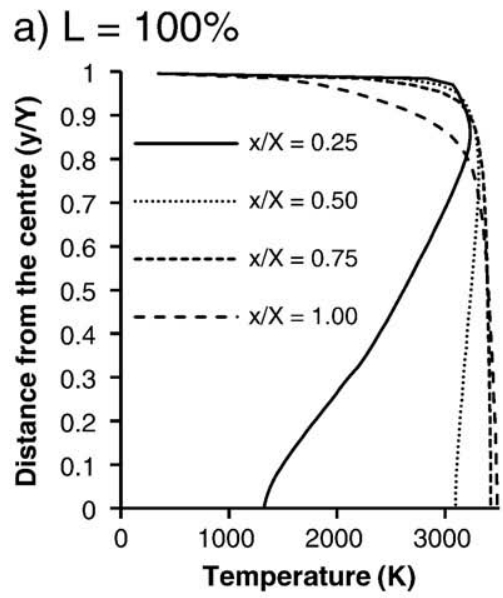

b) $\mathrm{L}=80 \%$

c) $\mathrm{L}=60 \%$
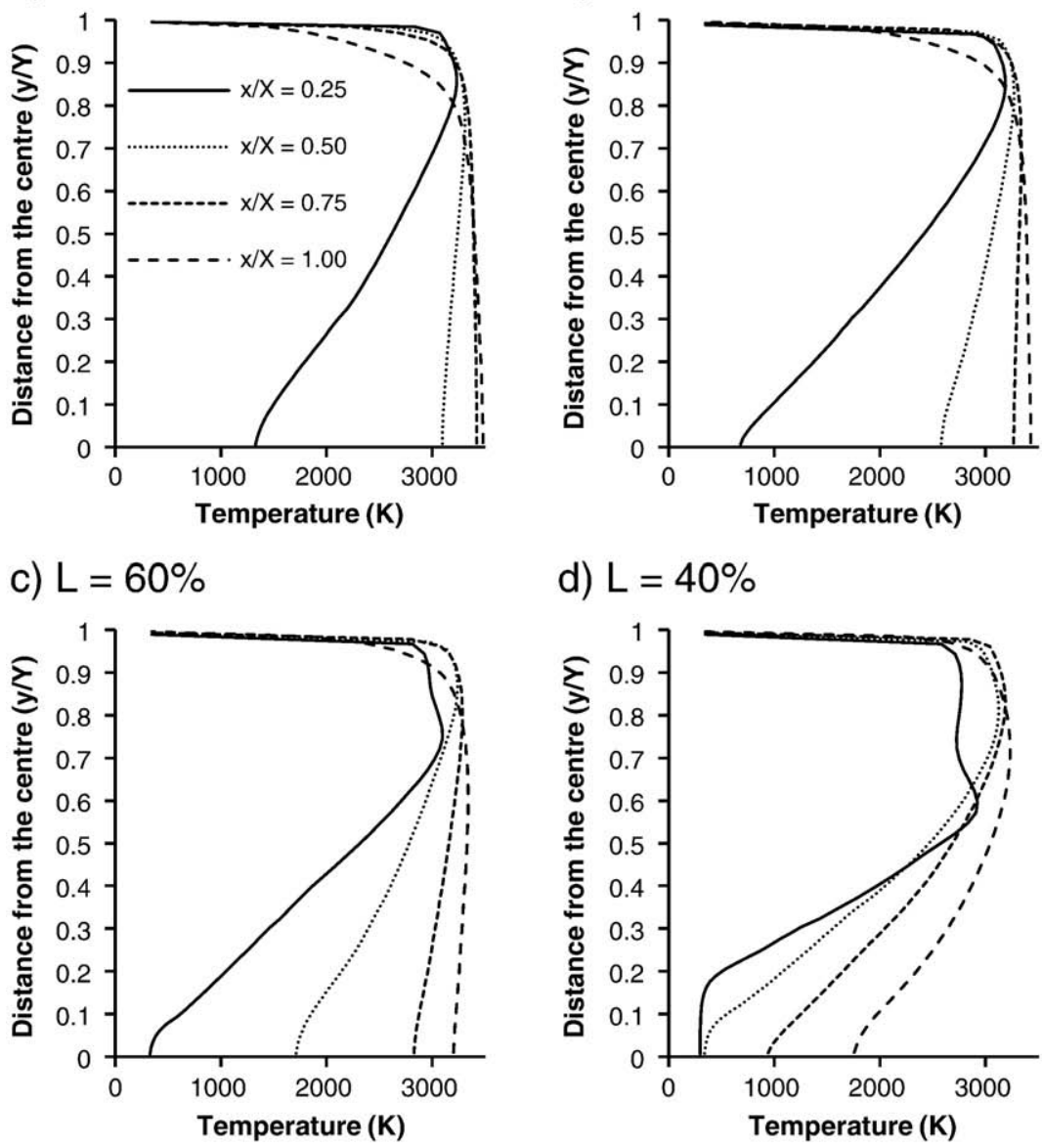

d) $\mathrm{L}=40 \%$

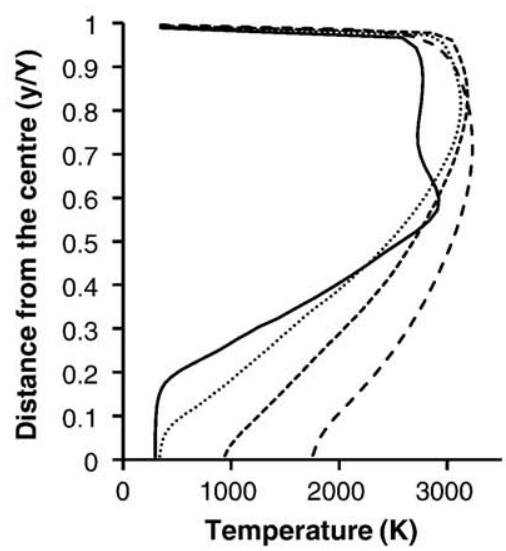

Fig. 16. Radial temperature profiles at quarterly intervals through the combustion for each tested combustion chamber length. 
gun using a commercial CFD code, Fluent 6.3. The results drawn from this model are summarized below:

- The core of the flame is significantly stretched by larger droplets. For fuel droplets greater than $5 \mu \mathrm{m}$ there is a risk of combustion occurring through convergent-divergent nozzle and barrel, which largely reduces the temperature around the powder inlet. However, for smaller droplets there is a negligible difference in velocity and temperature profiles through the system. Therefore, given the applied flow rates the fuel should be atomized below $5 \mu \mathrm{m}$ in order to achieve an optimum working performance. The degree of atomization is unlikely to make a significant difference on the heat conducted through the internal surface of the combustion chamber for droplets varying between 0.1 and $10 \mu \mathrm{m}$.

- The momentum output of the gas flow beyond the combustion chamber is increased by reducing the throat diameter of the convergent-divergent nozzle. The intensity of the under-expanded shock regime at the exit of the barrel is also reduced. A 20\% decrease in throat diameter creates a flow of almost perfect design condition. However, this reduction heightens the combustion chamber pressure by $60 \%$.

- A reduction in the combustion chamber length by $20 \%$ for the baseline model is possible without excessive fuel exiting the combustion chamber. This reduction makes a negligible difference to the temperature and velocity profiles through the system. The heat transferred through the internal surface of the combustion chamber can be expected to be reduced by at least the same factor due to the surface area reduction as well as the larger proportion of recirculation at the surface.

\section{References}

[1] S. Gu, C.N. Eastwick, K.A. Simmons, D.G. McCartney, J. Therm. Spray Technol. 10 (2001) 461

[2] W.D Swank, J.R. Fincke, D.C. Haggard, Proceedings of the 7th National Thermal Spray Conference, 1995, p. 20.

[3] D. Cheng, Q. Xu, G. Trapaga, E.J. Lavernia, Metall. Mater. Trans. 32 (2001) 1609.

[4] D. Zhang, S.J. Harris, D.G. McCartney, Mater. Sci. Eng. A 344 (2003) 45.

[5] D. Cheng, G. Trapaga, J.W. McKelliget, E.J. Lavernia, Model. Simul. Mater. Sci. Eng. 11 (2003) R1.

[6] M. Li, D. Shi, P.D. Christofides, Ind. Eng. Chem. Res. 43 (2004) 3632.

[7] M. Li, P.D. Christofides, Chem. Eng. Sci. 13 (2005) 3649.
[8] S. Kamnis, S. Gu, Chem. Eng. Sci. 61 (2006) 5427.

[9] S. Kamnis, S. Gu, N. Zeoli, Surf. Coat. Technol. 202 (2008) 2715.

[10] N. Zeoli, S. Gu, S. Kamnis, Comput. Chem. Eng. 32 (2008) 1661.

[11] X. Yang, S. Eidelman, J. Therm. Spray Technol. 5 (1996) 175.

[12] S.A. Morsi, A.J. Alexander, J. Fluid Mech. 5 (1972) 193.

[13] W.E. Ranz, W.R. Marshall, Chem. Eng. Prog. 48 (1952) 141.

[14] W.E. Ranz, W.R. Marshall, Chem. Eng. Prog. 48 (1952) 173.

[15] F.A. Williams, Combustion TheorySecond ed, Addison-Wesley, 1988.

[16] B.F. Magnussen, B.H. Hjertager, 16th International Symposium on Combustion, 1976.

\section{Glossary}

General symbols

$A_{p}$ : surface area of a droplet $\left(\mathrm{m}^{2}\right)$

$a_{1,2,3}$ : drag coefficient constants

$C_{D}$ : drag coefficient

$d$ : diameter $(\mathrm{m})$

$D_{i, m}$ : diffusion coefficient of vapour in the bulk flow $\left(\mathrm{m}^{2} \mathrm{~s}^{-1}\right)$

$F_{D}$ : drag force coefficient

$F_{x}$ : Additional acceleration term $\left(\mathrm{N} \mathrm{kg}^{-1}\right)$

$h$ : convective heat transfer coefficient $\left(\mathrm{W} \mathrm{m}^{-2} \mathrm{~K}^{-1}\right)$

$k$ : turbulent kinetic energy $\left(\mathrm{m}^{2} \mathrm{~s}^{-2}\right)$

$K_{\infty}$ : thermal conductivity of the continuous phase $\left(\mathrm{W} \mathrm{m}^{-1} \mathrm{~K}^{-1}\right)$

$K_{c}$ : mass transfer coefficient $\left(\mathrm{m} \mathrm{s}^{-1}\right)$

$m_{p}$ : mass of particle $(\mathrm{kg})$

$M_{\omega, i}:$ molecular weight of species $i\left(\mathrm{~kg} \mathrm{~mol}^{-1}\right)$

$N_{i}$ : molar flux of vapour $\left(\mathrm{kg} \mathrm{mol} \mathrm{m}^{-2} \mathrm{~s}^{-1}\right)$

$\mathrm{Nu}$ : Nusselt number

$p_{o p}$ : operating pressure $(\mathrm{Pa})$

Pr: Prandtl number

$p_{\text {sat: }}$ : saturated pressure $(\mathrm{Pa})$

$R$ : universal gas constant $\left(\mathrm{J} \mathrm{K}^{-1} \mathrm{~mol}^{-1}\right)$

Re: Reynolds number

$R e_{d}$ : Reynolds number based on the particle diameter

$s:$ particle path

Sc: Schmidt number

$t$ : time (s)

T: temperature $(\mathrm{K})$

$T_{L}$ : Lagrangian time integral

$u$ : velocity $\left(\mathrm{m} \mathrm{s}^{-1}\right)$

$X_{i}$ : local bulk mole fraction

Greek symbols

$\varepsilon$ : turbulence dissipation rate $\left(\mathrm{m}^{2} \mathrm{~s}^{-3}\right)$

$\mu$ : viscosity $\left(\mathrm{kgm}^{-1} \mathrm{~s}^{-1}\right)$

$\rho$ : density $\left(\mathrm{kg} \mathrm{m}^{-3}\right)$ 